\title{
Covered versus uncovered self-expandable metallic stents for palliation of malignant gastric outlet obstruction: a systematic review and meta-analysis
}

Ya-min Pan ${ }^{*}$, Ji Pan, Li-kun Guo, Min Qiu and Jia-jun Zhang

\begin{abstract}
Background: Self-expandable metallic stents (SEMSs) are widely used for palliation of malignant gastric outlet obstruction (GOO). There are two types of SEMS, covered and uncovered, each with its own advantages and disadvantages. We aimed to compare the efficacy and safety between uncovered and covered SEMSs in the palliation of malignant gastric outlet obstruction.
\end{abstract}

Methods: Databases including PubMed, EMBASE, the Cochrane Library, the Science Citation Index and momentous meeting abstracts were searched and evaluated by two reviewers independently.

Results: Nine trials involving 849 patients were analyzed. Meta-analysis showed there was no significant difference in technical success rate (RR 1.0,95\% Cl $[0.98,1.01])$, clinical success rate (RR 1.04, 95\% Cl $[0.98,1.11])$, post-stenting dysphagia score (WMD $-0.01,95 \% \mathrm{Cl}[-0.52,0.50])$, stent patency (WMD $-0.31,95 \% \mathrm{Cl}[-1.73,1.11])$, overall complications (RR 1.07, 95\% Cl $[0.87,1.32])$ and reintervention rate (RR 1.30, 95\% Cl $[0.92,1.83])$ between covered and uncovered SEMSs group. However, covered SEMSs were associated with higher migration rate (RR 3.48, 95\% Cl $[2.16,5.62], P<0.00001)$ and lower obstruction rate (RR $0.42,95 \% \mathrm{Cl}[0.24,0.73], \mathrm{P}=0.002)$.

Conclusions: In the palliative treatment of malignant gastric outlet obstruction, both covered and uncovered SEMSs are safely and effective. Covered stents can reduce the risk of restenosis, whereas uncovered stents are effective in decreasing stent migration.

Keywords: Covered SEMSs, Uncovered SEMSs, Gastric outlet obstruction, Meta-analysis

\section{Background}

Malignant gastric outlet obstruction (GOO) is recognized as a complication of advanced malignant disease in the upper gastrointestinal tract, which usually include distal gastric cancer, periampullary carcinoma, lymphoma and metastases to the duodenum [1,2]. GOO always leads to intractable vomiting, nausea, abdominal discomfort and poor oral food intake, which diminish quality of life. Compared with palliative gastrojejunostomy or other surgical procedures, self-expandable metallic stents (SEMSs) can rapidly relieve obstructive symptoms with fewer complications and mortality $[3,4]$. There are two types of SEMSs, covered and

\footnotetext{
* Correspondence: Panyamin2014@163.com

Department of Endoscopy, Shu-guang Hospital Affiliated to Shanghai University of Traditional Chinese Medicine, 201203 Shanghai, China
}

uncovered type; both of them are widely used for palliation of GOO [5-7], each with its own advantages and disadvantages.

To the best of our knowledge, a systematic review [8] on this topic has been published. More recently, additional studies have been published and some conflicting results have emerged. Therefore, we believe an updated systemic review and meta-analysis is required to evaluate the efficacy and safety between uncovered and covered SEMSs for palliation of malignant gastric outlet obstruction.

\section{Methods}

Study identification and eligibility criteria

This study has been approved by ethics committee of Shu-guang Hospital Affiliated to Shanghai University of 
Traditional Chinese Medicine. A comprehensive literature search was done to identify all relevant studies that compared covered stents with uncovered stents in the palliation of malignant gastric outlet obstruction. The PubMed, EMBASE, the Cochrane Library and the Science Citation Index were searched systematically for all articles published up to Dec.2013, without language restriction, which included the following terms in their titles, abstracts, or keywords lists: "gastroduodenal obstruction", "covered stent", "uncovered stent", "malignant gastric outlet obstruction". The references in retrieved articles were also screened manually. The abstracts of United European Gastroenterology week (UEGW) and Digestive Disease Week (DDW) were also searched systematically.

The inclusion criteria were as follows: (1) RCTs and nonrandomized prospective and retrospective studies; (2) analyses of both uncovered stents and covered stents; (3) patients were diagnosed malignant gastric outlet obstruction; (4) outcome measures included technical and clinical success, overall complications, stent patency and reintervention rate; (5) when multiple articles published by the same team from the same institute within the same study interval were identified, only the latest or the most detailed and informative article, or the one with the best quality in methodology, was included. Commentaries, case reports, reviews, or guidelines were excluded.

\section{Data extraction}

Two reviewers (YM.P and J.P) abstracted data independently and reached consensus on all items. Data were extracted on: first author; year of publication; study interval; number of patients; age and sex; study design, stent characteristics; technical success rate; clinical success rate; stent obstruction; stent migration; overall complications; reintervention rate; stent patency and GOO scoring system (GOOSS).

\section{Assessment of methodological quality}

The quality of all studies was assessed by using the Newcastle-Ottawa Scale with some modifications to match the needs for this meta-analysis [9]. The quality of the studies was evaluated by examining three items: patient selection, comparability of study groups, and assessment of outcome. Studies achieving five or more stars were considered high quality. Methodological quality assessment was independently carried out by two of the authors. Any disagreement was resolved by consensus.

\section{Statistical analysis}

Statistical manipulation was performed with Review Manager Software (Version 5.1, Windows, Nordic Cochrane Center, Copenhagen, Denmark). Values for analysis were extracted from published reports or calculated from crude data. For summary statistics in meta-analyses, the Relative
Risk (RR) is recommended for dichotomous data, and the Weighted Mean Difference (WMD) is recommended for continuous data. Pooled estimates were presented with a 95\% confidence interval. $\mathrm{P}<0.05$ was considered significant. A sensitivity analysis [10] determined how the results would be influenced if one study was removed from the analysis for each outcome; this indicates the extent to which the results are (or are not) robust to assumptions and decisions that were made when carrying out the synthesis. Because of the anticipated clinical heterogeneity across the included studies, we decided to use only the random effect model before pooling data. This adjusts for variability of results among studies and provides a more conservative estimate of an effect by using a wider confidence interval [11].

\section{Results}

\section{Identification of eligible studies}

The literature search yielded 382 abstracts for review. Finally, 9 trials [5-7,12-17] were included (Figure 1). 3 trials $[5,14,16]$ were randomized clinical trials, 5 trials $[6,7,12,15,17]$ were retrospective studies and one report [13] was prospective study. The combined studies enrolled 849 patients, of whom 380 underwent covered stents placement and 469 with uncovered stents. The characteristics of included trials were listed in Table 1. The quality assessment and scores are summarized in Table 1. Seven studies scored five or more stars on the modified Newcastle Ottawa Scale [5,12-17]. Characteristics of stents were not consistent in all studies (Table 2). More than two types of stents were used in 3 trials $[14,15,17]$.

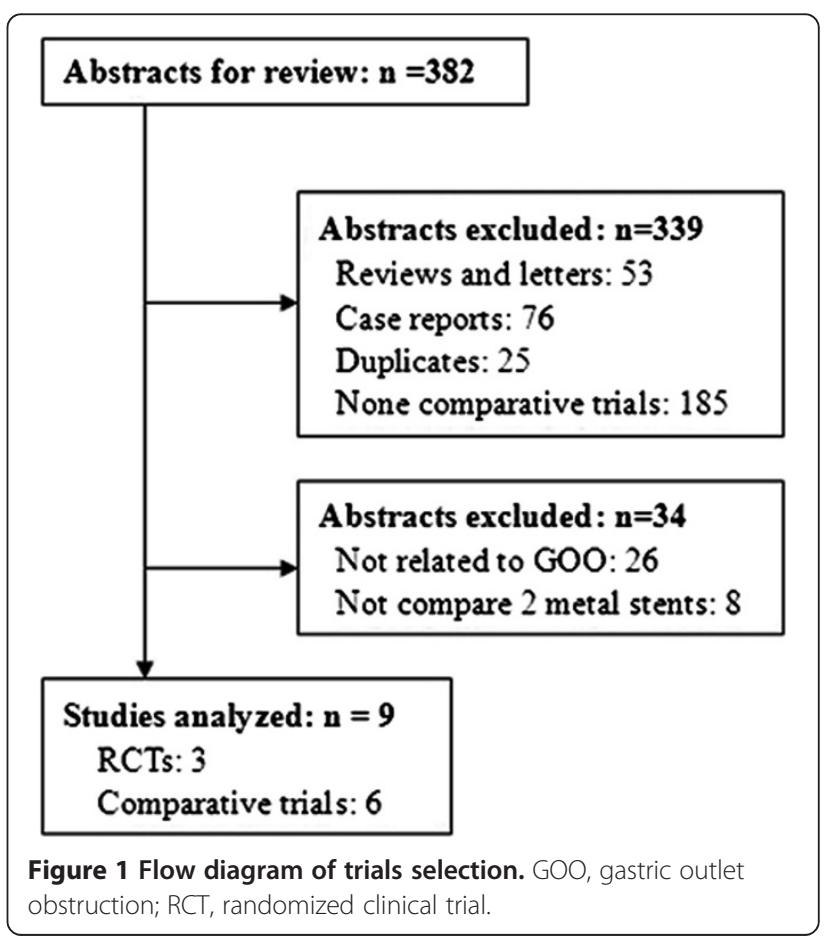


Table 1 Characteristics of the included studies

\begin{tabular}{|c|c|c|c|c|c|c|c|c|c|}
\hline Study author & Year & Design & $\begin{array}{c}\text { Study } \\
\text { interval (y) }\end{array}$ & $\begin{array}{c}\text { Patients }(n) \\
\text { covered/uncovered }\end{array}$ & $\begin{array}{c}\text { Age }(M, y) \\
\text { covered/uncovered }\end{array}$ & $\begin{array}{c}\text { Female } \\
(\mathrm{n}, \%)\end{array}$ & $\begin{array}{c}\text { Disease } \\
\text { diagnosis (n) }\end{array}$ & Matching & $\begin{array}{l}\text { Quality } \\
\text { score }\left(^{*}\right)\end{array}$ \\
\hline Yu Kyung Cho [5] & 2004 & $\mathrm{RCT}$ & NR & $13 / 12$ & $65.0^{\S}$ & $12(48 \%)$ & $\mathrm{GC}(25)$ & $1,2,3$ & $* * * * *$ \\
\hline Jong Pil Im [6] & 2008 & R & $2005-2006$ & $24 / 18$ & $60.7^{\S}$ & $7(16 \%)$ & $\begin{array}{l}\mathrm{GC}(26) / \mathrm{PC}(12) \\
\text { /Others(13) }\end{array}$ & NR & $* * * *$ \\
\hline Seungmin Bang [7] & 2008 & $\mathrm{R}$ & 1998-2003 & $53 / 79$ & $58.0 / 59.0$ & $40(30 \%)$ & $\begin{array}{l}\mathrm{GC}(109) / \mathrm{PC}(13) \\
\text { /Others(12) }\end{array}$ & NR & $* * *$ \\
\hline Iruru Maetani [12] & 2009 & $\mathrm{R}$ & 1998-2006 & $29 / 31$ & $70.6 / 72.2$ & $27(45 \%)$ & $\begin{array}{l}\text { GC(28)/PC(20)/ } \\
\text { Others }(12)\end{array}$ & $1,2,3,4,5$ & $* * * * *$ \\
\hline Kee Myung Lee [13] & 2009 & $P$ & 1998-2007 & $70 / 84$ & $67.2 / 63.3$ & $48(31 \%)$ & $\begin{array}{l}\text { GC(122)/PC(19) } \\
\text { /Others(13) }\end{array}$ & $1,2,3,5$ & $* * * * *$ \\
\hline Chan Gyoo Kim [14] & 2010 & $\mathrm{RCT}$ & $2003-2007$ & $40 / 40$ & $58.0 / 57.0$ & $17(21 \%)$ & $\mathrm{GC}(80)$ & $1,2,3,4,5$ & $* * * * * *$ \\
\hline Chan Ik Park [15] & 2012 & $\mathrm{R}$ & $2006-2011$ & $96 / 128$ & $64.0 / 65.0$ & $15(17 \%)$ & GC(224) & $1,2,5$ & $* * * * *$ \\
\hline Iruru Maetani [16] & 2013 & $\mathrm{RCT}$ & $2007-2010$ & $31 / 31$ & $69.4 / 68.1$ & $32(52 \%)$ & $\begin{array}{l}\mathrm{GC}(27) / \mathrm{PC}(26) \\
\text { /Others(9) }\end{array}$ & $1,2,3,4,5$ & $* * * * * *$ \\
\hline Sang Myung Woo [17] & 2013 & $\mathrm{R}$ & 2003-2010 & $24 / 46$ & $62.0 / 61.0$ & $30(43 \%)$ & PC(46) /Others(24) & $1,2,3,4,5$ & $* * * * *$ \\
\hline
\end{tabular}

$\mathrm{R}$, retrospective; $\mathrm{P}$, prospective; $\mathrm{RCT}$, randomized control trial; $\mathrm{NR}$, not reported.

$\$$, mean age of all patients; $\left({ }^{*}\right)$, star rating $(\max 9)$.

Matching: 1 , age; 2 , sex; 3 , diagnosis; 4 , site of obstruction; 5 , previous treatment.

$\mathrm{GC}$, gastric cancer; $\mathrm{PC}$, pancreatic cancer.

Others, including gallbladder cancer, bile duct cancer, ampullary cancer, duodenal cancer and metastasis.

The main composition of covered materials is polytetrafluoroethylene membrane or polyurethane membrane.

\section{Technical and clinical success rate}

All trials assessed the technical success rate related to stenting procedure, and 6 trials [12-17] assessed the clinical success rate. Meta-analysis showed that there was no significant difference in technical success rate (RR 1.00, 95\% CI $[0.98,1.01]$ ) (Figure 2a) and clinical success rate (RR 1.04, 95\% CI $[0.98,1.11]$ ) (Figure 2b). The post-stenting GOOSS was recorded in 6 trials [5,12-16], there was no significant difference between covered and uncovered stents group $(P=0.96)$ (Figure 3a).

\section{Stent patency}

The stent patency was reported in 6 studies [6,13-17]. The median patency duration was 9 to 23 weeks with covered stents and 10 to 22 weeks with uncovered stents respectively. Meta-analysis showed there was no significant difference between covered and uncovered stents group (WMD -0.31, 95\% CI [-1.73, 1.11]) (Figure 3b). Chemotherapy after endoscopic stenting was reported in 6 studies, totally $42.7 \%(270 / 632)$ patients underwent chemotherapy. All studies reported that palliative chemotherapy was not associated with stent patency.

\section{Complications and reintervention}

Meta-analysis showed there were no significant difference in overall complications between covered and uncovered stents group $(\mathrm{P}=0.54)$ (Figure 4c). However, covered stents were associated with higher stent migration (RR 3.48, 95\% CI [2.16, 5.62]) (Figure 4a), and uncovered stents were associated with higher stent obstruction (RR 0.42, 95\% CI [0.24, 0.73]) (Figure 4b) in subgroup analysis. Reintervention for stent-related complications was reported in 6 studies [5,12-15,17]. Meta-analysis showed there was no significant difference in reintervention rate between two groups $(P=0.13)$ (Figure $4 d$ ).

\section{Sensitivity analysis}

The results of sensitivity analysis are listed in Table 3 . When high quality studies were analyzed (Star $\geq 5$ ), meta-analysis showed there was no significant difference in technical success rate, clinical success rate, stent patency, overall complications, Post-stenting GOOSS and reinterventioon rate between two groups. Covered stents were associated with higher stent migration rate (RR 3.49, 95\% CI [1.92, 6.32]) and lower stent obstruction rate (RR 0.39, 95\% CI [0.18, 0.84]) compared to uncovered stents. In the studies containing $\mathrm{N} \geq 70$ patients, meta-analysis showed the same results. Data were also analyzed by random effects models. Sensitivity analysis showed that the results were robust.

\section{Discussion}

Malignant gastric outlet obstruction without effective intervention would result in progressive deterioration and death [3]. Surgical bypass has been the standard treatment, but it is associated with significantly high morbidity and mortality. Endoscopic stenting is an alternative treatment, which palliates malignant obstruction with lower morbidity and mortality [4]. There are two types SEMSs widely used in clinical, covered and uncovered. Which is better? Maetani et al. [6] reported covered stents were associated with more frequent need for reintervention 
Table 2 Stent characteristics of the included studies

\begin{tabular}{|c|c|c|c|c|c|c|}
\hline Study/author & Group & Stent type & Stent material & Stent diameter $(\mathrm{mm})$ & Stent length $(\mathrm{cm})$ & Covered material \\
\hline \multirow[t]{2}{*}{ Yu Kyung Cho } & Covered & $N R$ & Nickel-Titanium & $N R$ & NR & NR \\
\hline & Uncovered & & Nickel-Titanium & & & \\
\hline \multirow[t]{2}{*}{ Jong Pil Im } & Covered & NR & & 18 & $9 / 11$ & \\
\hline & Uncovered & & NR & 18 & $11 / 12 / 16$ & NR \\
\hline \multirow[t]{2}{*}{ Seungmin Bang } & Covered & Niti-S & NR & $20 / 22$ & $6-15$ & \\
\hline & Uncovered & Niti-S & & $20 / 22$ & $6-15$ & PU \\
\hline \multirow[t]{2}{*}{ Iruru Maetani } & Covered & Ultraflex & NR & $18 / 23$ & $10 / 12 / 15$ & \\
\hline & Uncovered & Ultraflex & & $18 / 23$ & $10 / 12 / 15$ & PTFE \\
\hline \multirow[t]{2}{*}{ Kee Myung Lee } & Covered & Niti-S & Nitinol & 18 & $6 / 8 / 10$ & \\
\hline & Uncovered & Niti-S & Nickel-Titanium & 18 & $6 / 8 / 10$ & PU \\
\hline \multirow[t]{2}{*}{ Chan Gyoo Kim } & Covered & Niti-S & Nitinol & $18 / 20$ & $8 / 10 / 12$ & \\
\hline & Uncovered & Wallstent/Wallflex & Elgiloy/Nitinol & $20 / 22$ & $6 / 9 / 12$ & PTFE \\
\hline \multirow[t]{2}{*}{ Chan Ik Park } & Covered & Niti-s & Nitinol & $N R$ & $6-16$ & \\
\hline & Uncovered & Wallstent/Hanaro & Elgiloy/Nitinol & & $6-16$ & PU \\
\hline \multirow[t]{2}{*}{ Iruru Maetani } & Covered & Niti-S & Nitinol & 20 & & \\
\hline & Uncovered & Comvi & Nitinol & 20 & NR & PTFE \\
\hline \multirow[t]{2}{*}{ Sang Myung Woo } & Covered & Niti-s/Bona & & $18-22$ & $4-12$ & \\
\hline & Uncovered & Niti-s/Bona/Wallflex & NR & $18-22$ & $4-12$ & $N R$ \\
\hline
\end{tabular}

PTEF, polytetrafluoroethylene; PU, polyurethane.

Niti-S (Taewoon Inc. South Korea); Bona (Standard SciTech Inc. Seoul, Korea).

Hanaro (M.I. Tech. Seoul, Korea).

Wallflex (Boston Scientific, USA); Wallstent (Boston Scientific, USA).

Ultraflex (Boston Scientific, USA).

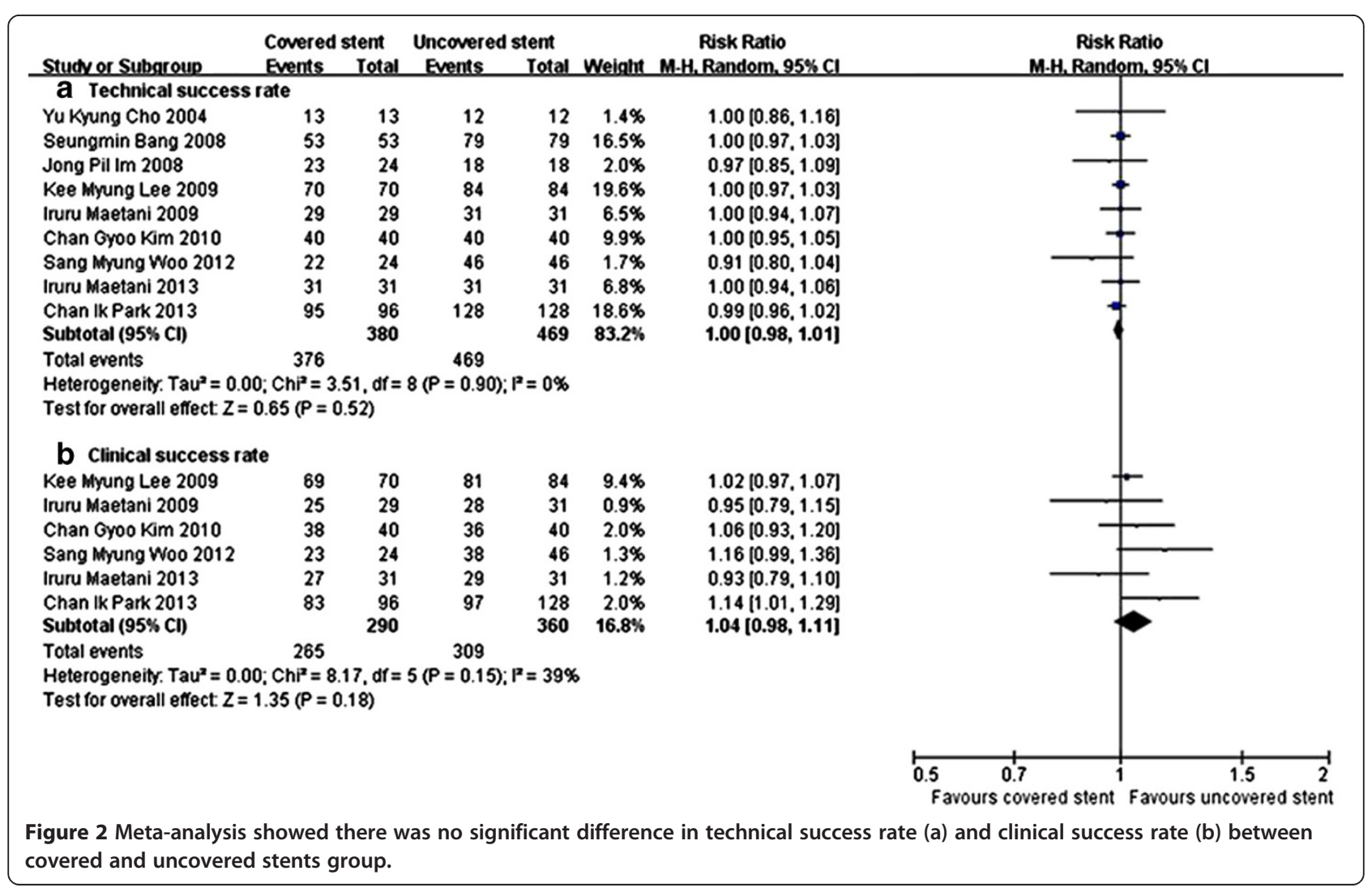


than uncovered stents. Kim et al. [14] reported both covered and uncovered SEMSs were effective and safe in treatment of patients. Recently, a systematic review [8] on this topic has been published. However, only two RCTs related to GOO were included for analysis in this systematic review, the number of included patients may be too small to make effective statistic analysis. More recently, additional studies have been published and some conflicting results have emerged. Therefore, we believe an updated systemic review and meta-analysis is required to evaluate the efficacy and safety between uncovered and covered SEMSs.

In this meta-analysis, there was no significantly difference between uncovered and covered stents in technical and clinical success rates. Endoscopic stenting was deployed through a guide wire, when the guide wire could not pass the stricture, and then the stent could not be deployed successfully. So the success of stenting is affected by the degree of narrowing and tortuosity of the stricture rather than the difference between the types of stent used.

The GOOSS was used to evaluate the severity of obstructive symptom, the GOOSS assigns a point score depending on the patient's level of oral intake (no oral intake, 0 ; liquids only, 1; soft solids, 2; low-residue or full diet, 3) [18]. Most of patients could not intake any fluid before stenting, though most included studies were retrospective, the patients' characteristics were similar in baseline. There was significant difference in GOOSS prestenting and post-stenting, but there was no difference between covered and uncovered stents after stenting.
These mean that both stents have similar effect in palliation of malignant obstruction.

Stent patency is an important factor in QOL of patients. Meta-analysis showed there was no significant difference in stent patency between two groups. The main cause influencing patency was stent migration in covered stent group and stent obstruction in uncovered stent group respectively. The covered stent was associated with advantage of preventing tumor ingrowth, but this advantage was offsetted by high migration. Chemotherapy after stent placement could be independently associated with prolonged stent patency, because chemotherapy may stabilize or decrease tumor burden and thereby decrease malignant ingrowth or overgrowth. Some studies $[19,20]$ reported chemotherapy after stent placement contributed to longer durations of stent patency in gastric cancer patients. However, we could not find any association of stent patency with palliative chemotherapy after stent placement in included studies. Further prospective randomized trials are needed to determine the role of chemotherapy.

Complications included stent obstruction, stent migration, bleeding, stent fracture, perforation and others, the most complications were stent obstruction and migration. There was no difference in overall complications between the covered stent group and uncovered stent group. One study [21] has shown that covered stents placed in the biliary tract prevent tumor ingrowth without increasing migration frequency. However, in subgroup analysis, our meta-analysis showed that stent 


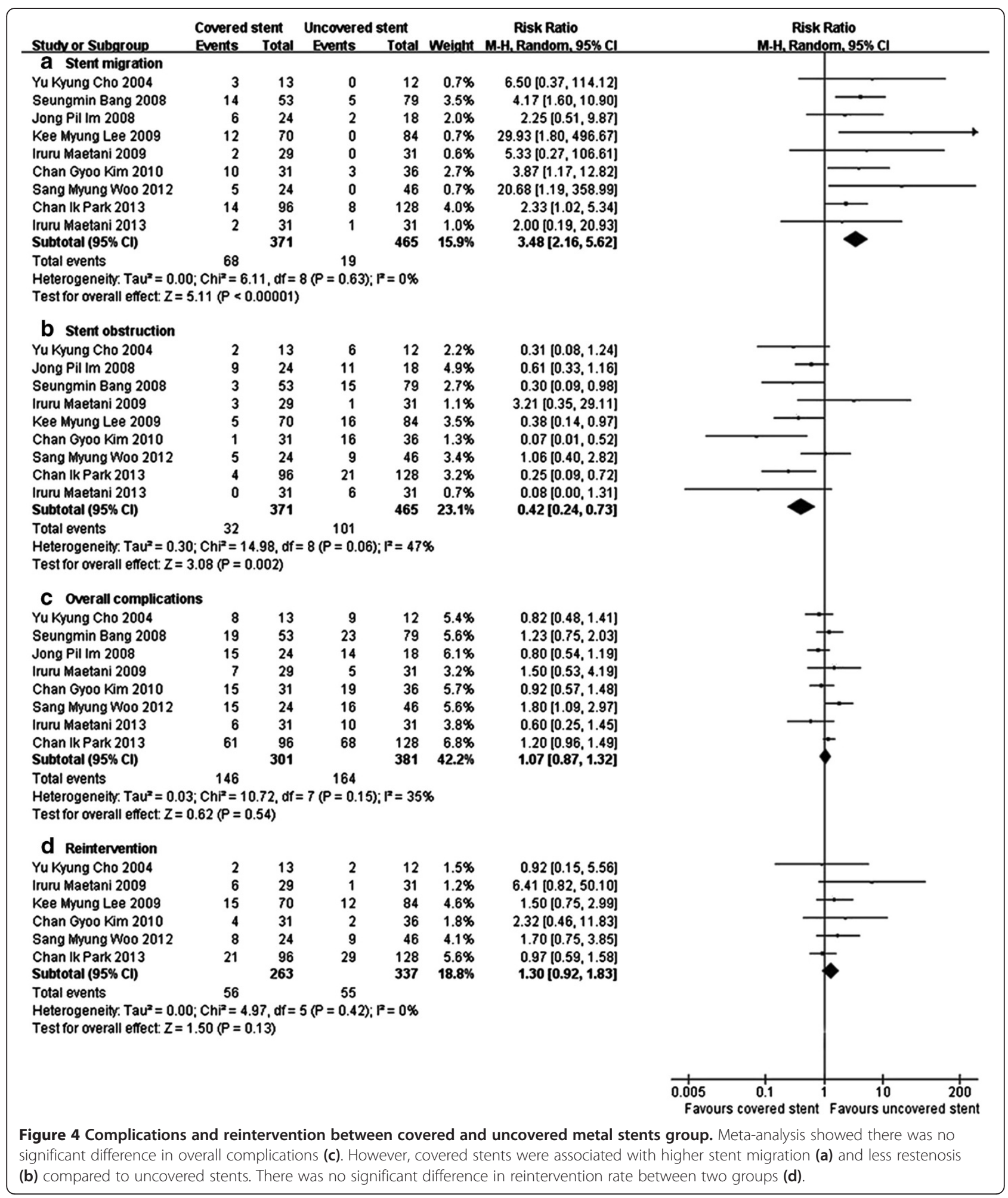

migration was more frequent in the covered stent group, which is maybe the expansion force of the covered stent is transferred to the intestinal wall through the covering membrane rather than through the wire mesh, and the friction between stent and tumor might not be enough to keep the stent stationary. The cause of stent obstruction included tumor ingrowth and overgrowth. Meta-analysis showed uncovered stents were associated with higher stent obstruction compared to covered stents, because uncovered stents are often associated with tumor ingrowth through 
Table 3 Sensitivity analysis

\begin{tabular}{|c|c|c|c|c|c|}
\hline Primary outcome & No. studies & No. patients & $\begin{array}{c}\text { Rate (\%) } \\
\text { (Covered/Uncovered) }\end{array}$ & $\begin{array}{l}\text { RR/WMD } \\
(95 \% \mathrm{Cl})\end{array}$ & P-value \\
\hline \multicolumn{6}{|c|}{ High quality studies(Star $\geq 5$ ) } \\
\hline Technical success rate & 7 & 675 & $99.0 / 100$ & $0.99[0.98,1.01]$ & 0.51 \\
\hline Clinical success rate & 6 & 650 & $91.4 / 85.8$ & $1.04[0.98,1.11]$ & 0.18 \\
\hline Post-stenting GOOSS & 6 & 451 & - & $-0.01[-0.52,0.50]^{*}$ & 0.96 \\
\hline Stent pantency & 5 & 590 & - & $-0.05[-1.50,1.39]^{*}$ & 0.94 \\
\hline Stent migration & 7 & 662 & $16.3 / 3.3$ & $3.49[1.92,6.32]$ & $<0.0001$ \\
\hline Stent obstruction & 7 & 662 & $6.8 / 20.4$ & $0.39[0.18,0.84]$ & 0.02 \\
\hline Overall complications & 6 & 508 & $50.0 / 44.7$ & $1.11[0.86,1.44]$ & 0.43 \\
\hline Reintervention rate & 6 & 600 & $21.3 / 16.3$ & $1.30[0.92,1.83]$ & 0.13 \\
\hline \multicolumn{6}{|c|}{ Studies containing $\geq 70$ patients } \\
\hline Technical success rate & 5 & 660 & $98.9 / 100$ & $1.00[0.98,1.01]$ & 0.53 \\
\hline Clinical success rate & 4 & 528 & $92.6 / 84.6$ & $1.08[0.99,1.18]$ & 0.08 \\
\hline Post-stenting GOOSS & 3 & 304 & - & $0.26[-0.05,0.48]^{*}$ & 0.06 \\
\hline Stent pantency & 4 & 528 & - & $0.62[-0.06,1.18]^{*}$ & 0.07 \\
\hline Stent migration & 5 & 647 & 20.1/4.3 & $4.00[2.05,7.80]$ & $<0.0001$ \\
\hline Stent obstruction & 5 & 647 & $6.6 / 20.6$ & $0.35[0.17,0.74]$ & 0.006 \\
\hline Overall complications & 4 & 493 & $53.9 / 43.6$ & $1.22[0.99,1.51]$ & 0.06 \\
\hline Reintervention rate & 4 & 515 & 21.7/17.7 & $1.25[0.88,1.78]$ & 0.21 \\
\hline
\end{tabular}

$\mathrm{R}$, retrospective trial; $\mathrm{P}$, prospective trial; $\mathrm{RCT}$, randomized control trial. *, WMD $(95 \% \mathrm{Cl})$.

GOOSS, gastric outlet obstruction scoring system.

the stent mesh. 3 trials reported the tumor overgrowth rate; there was no significant difference between two groups. When stent migration or stent obstruction occurred, endoscopic or surgical interventions should be taken. Though 3 trials reported uncovered stent was associated with lower re-intervention rate, meta-analysis showed there was no significant difference between covered and uncovered stents.

Several limitations of the present study need to be considered. First, there was significant heterogeneity for main outcomes. The source of heterogeneity may include the different publishing time of studies, the study design (6 none-RCT studies), the selection criteria, the characteristic of patients and stents. Though the data was treated with random effect models, there was still some influence to final results. Second, included studies were associated with small sample sizes, different levels of the intervention, different follow-up duration; those could also influence the results. Third, there were many different causes of GOO, which including gastric cancer, pancreatic cancer and others. The different characteristic of diseases might lead to different stent patency and complications. Fourth, the selective reporting of studies with positive results may result in overestimation of technical, clinical success rate and stent patency, and cause some bias to our meta-analysis.

\section{Conclusions}

Both covered and uncovered SEMSs are technically feasible and effective in the palliative treatment of malignant gastric outlet obstruction. Meta-analysis showed there was no significant difference in stent patency, overall complications and reintervention; whereas in subgroup analysis, stent obstruction was more frequent with covered stents, and stent migration occurred more frequently with uncovered stents. The retrospective nature of these reports and their small sample sizes suggest that prospective controlled trials with large sample sizes are required to confirm the results of the current meta-analysis.

\section{Consent}

Written informed consent was obtained from the patient for the publication of this report and any accompanying images.

\section{Competing interests}

The authors declare that they have no competing interest.

\section{Authors' contributions}

Y-M.P and J.P participated in abstracts search; Y-M.P and L-K.G participated in data extraction; Y-M.P and M.Q participated in the design of the study and performed the statistical analysis; J-J.Z conceived of the study, and participated in its design and coordination; all authors read and approved the final manuscript.

Acknowledgment

We thank Dr Jun Wu for his statistical support in meta-analysis. 
Received: 28 April 2014 Accepted: 24 September 2014

Published: 30 September 2014

\section{Reference}

1. Kikuchi S, Tsutsumi O, Kobayashi N, Tsukamoto H, Shimao H, Sakakibara Y, Hiki Y, Kakita A: Does gastrojejunostomy for unresectable cancer of the gastric antrum offer satisfactory palliation? Hepatogastroenterology 1999, 46:584-587.

2. Smith JW, Brennan MF: Surgical treatment of gastric cancer. Proximal, mid, and distal stomach. Surg Clin North Am 1992, 72:381-399.

3. Mehta S, Hindmarsh A, Cheong E, Saada J, Tighe R, Lewis MP, Rhodes M: Prospective randomized trial of laparoscopic gastrojejunostomy versus duodenal stenting for malignant gastric outflow obstruction. Surg Endosc 2006, 20:239-242.

4. Hosono S, Ohtani H, Arimoto Y, Kanamiya Y: Endoscopic stenting versus surgical gastroenterostomy for palliation of malignant gastroduodenal obstruction: a meta-analysis. J Gastroenterol 2007, 42:283-290.

5. Yu Kyung C, Sang Woo K, Se Hee K, Park JY: The comparison of covered and uncovered expandable metal stents in the palliation of malignant gastric outlet obstruction. Gastrointest Endosc 2004, 59:M1797.

6. Im JP, Kang JM, Kim SG, Kim JS, Jung HC, Song IS: Clinical outcomes and patency of self-expanding metal stents in patients with malignant upper gastrointestinal obstruction. Dig Dis Sci 2008, 53:938-945.

7. Bang S, Kim HJ, Park JY, Park YS, Kim MH, Park SW, Lee YC, Song SY: Effectiveness of self-expanding metal stents for malignant antropyloric and duodenal obstruction with a comparison between covered and uncovered stents. Hepatogastroenterology 2008, 55:2091-2095.

8. Yang Z, Wu Q, Wang F, Ye X, Qi X, Fan D: A systematic review and meta-analysis of randomized trials and prospective studies comparing covered and bare self-expandable metal stents for the treatment of malignant obstruction in the digestive tract. Int J Med Sci 2013, 10:825-835.

9. Stang A: Critical evaluation of the Newcastle-Ottawa scale for the assessment of the quality of nonrandomized studies in meta-analyses. Eur J Epidemiol 2010, 25:603-605.

10. Sterne JA, Egger M, Smith GD: Systematic reviews in health care: Investigating and dealing with publication and other biases in meta-analysis. BMJ 2001, 323:101-105.

11. Berlin JA, Laird NM, Sacks HS: A comparison of statistical methods for combining event rates from clinical trials. Stat Med 1989, 8:141-151.

12. Maetani I, Ukita T, Tada T, Shigoka H, Omuta S, Endo T: Metallic stents for gastric outlet obstruction: reintervention rate is lower with uncovered versus covered stents, despite similar outcomes. Gastrointest Endosc 2009, 69:806-812.

13. Lee KM, Choi SJ, Shin SJ, Hwang JC, Lim SG, Jung JY, Yoo BM, Cho SW, Kim $\mathrm{JH}$ : Palliative treatment of malignant gastroduodenal obstruction with metallic stent: prospective comparison of covered and uncovered stents. Scand J Gastroenterol 2009, 44:846-852.

14. Kim CG, Choi IJ, Lee JY, Cho SJ, Park SR, Lee JH, Ryu KW, Kim YW, Park YI: Covered versus uncovered self-expandable metallic stents for palliation of malignant pyloric obstruction in gastric cancer patients: a randomized, prospective study. Gastrointest Endosc 2010, 72:25-32.

15. Park Cl, Kim JH, Lee YC, Jahng J, Youn YH, Park H, Lee SI: What is the ideal stent as initial intervention for malignant gastric outlet obstruction? Dig Liver Dis 2013, 45:33-37.

16. Maetani I, Mizumoto Y, Shigoka H, Omuta S, Saito M, Tokuhisa J, Morizane T: Placement of a triple-layered covered versus uncovered metallic stent for palliation of malignant gastric outlet obstruction: A multicenter randomized trial. Dig Endosc 2014, 26:192-199. doi:10.1111/den.12117. [Epub ahead of print].

17. Woo SM, Kim DH, Lee WJ, Park KW, Park SJ, Han SS, Kim TH, Koh YH, Kim $H B$, Hong EK: Comparison of uncovered and covered stents for the treatment of malignant duodenal obstruction caused by pancreaticobiliary cancer. Surg Endosc 2013, 27(6):2031-2039.

18. Adler DG, Baron TH: Endoscopic palliation of malignant gastric outlet obstruction using self-expanding metal stents: experience in 36 patients. Am J Gastroenterol 2002, 97:72-78.

19. Kim JH, Song HY, Shin JH, Choi E, Kim TW, Jung HY, Lee GH, Lee SK, Kim $\mathrm{MH}$, Ryu MH, Kang YK, Kim BS, Yook JH: Metallic stent placement in the palliative treatment of malignant gastroduodenal obstructions: prospective evaluation of results and factors influencing outcome in 213 patients. Gastrointest Endosc 2007, 66:256-264.
20. Cho YK, Kim SW, Hur WH, Nam KW, Chang JH, Park JM, Lee IS, Choi MG, Chung IS: Clinical outcomes of self-expandable metal stent and prognostic factors for stent patency in gastric outlet obstruction caused by gastric cancer. Dig Dis Sci 2010, 55:668-674.

21. Isayama H, Komatsu Y, Tsujino T, Sasahira N, Hirano K, Toda N, Nakai Y, Yamamoto N, Tada M, Yoshida H, Shiratori Y, Kawabe T, Omata M: A prospective randomized study of "covered" versus "uncovered" diamond stents for the management of distal malignant biliary obstruction. Gut 2004, 53:729-734.

doi:10.1186/1471-230X-14-170

Cite this article as: Pan et al:: Covered versus uncovered self-expandable metallic stents for palliation of malignant gastric outlet obstruction: a systematic review and meta-analysis. BMC Gastroenterology 2014 14:170.

\section{Submit your next manuscript to BioMed Central and take full advantage of:}

- Convenient online submission

- Thorough peer review

- No space constraints or color figure charges

- Immediate publication on acceptance

- Inclusion in PubMed, CAS, Scopus and Google Scholar

- Research which is freely available for redistribution

Submit your manuscript at www.biomedcentral.com/submit
C Biomed Central 